\title{
AN EIGHTEENTH-CENTURY SURGEON AND APOTHECARY: WILLIAM ELMHIRST (1721-1773)
}

\author{
by
}

\section{E. M. SIGSWORTH AND P. SWAN*}

ALTHOUGH general accounts of the eighteenth-century development of the medical profession exist, in particular that by Bernice Hamilton, ${ }^{1}$ it is rare to be allowed an insight into the day-by-day practice of medicine. ${ }^{2}$ The survival of William Elmhirst's medical ledger for the years between 1768 and his untimely death in 1773 chronicles in great detail not only the accounts of his dealings with patients but, as is characteristic of the unsystematic methods of bookkeeping which were then common, many references to the farming activities which he combined with his medical practice. ${ }^{3}$

Born in 1721, William Elmhirst was a descendant of an old-established family traceable back at least as far as 1320 when John Genne of Ouslethwaite, near Barnsley, married a daughter of John Elmhirst. ${ }^{4}$ There were further intermarriages between the two families, and it was therefore fitting that William Elmhirst should, for the greater part of his life, live at Genn House, a sturdy stone dwelling which came fully into possession of the family in the mid-seventeenth century, at about the time when the substantial barn was erected, bearing the date 1659.5 Although situated approximately rather less than two miles from the centre of Barnsley, Genn House retains its rural ambience and must appear very similar to what it was when at the centre of William Elmhirst's busy practice. It is only a short distance down the slope into Worsborough Dale to the half-timbered house at Houndhill which is the residence of the present head of the family, Mr. A. O. Elmhirst, to whom the authors are indebted for drawing attention to the existence of his medical ancestor's ledger.

William Elmhirst completed his apprenticeship in June 1743 and was admitted to

* Hull College of Higher Education.

1 'The medical professions in the eighteenth century', Econ. Hist. Rev., 2nd series IV, 1951.

${ }^{2}$ Articles relating to contemporary medical practice are usually based upon diaries rather than, as in this case, the actual accounts with their medical and financial details. See, for example, W. Brockbank, 'Country practice in days gone by. Pt 1', Med. Hist., 1960, 4: 65-69, p. 65; W. Brockbank and M. L. Kay, 'Extracts from the diary of Richard Kay of Baldingstone, Bury, surgeon (1737-50)', ibid., 1959, 3: 58-68; J. Rendle-Short, 'William Cadogan, eighteenth-century physician', ibid., 1960, 4: 288-309; A. Batty Shaw, 'Benjamin Gooch, eighteenth-century Norfolk surgeon', ibid., 1972, 14: 40-50. Also, W. Brockbank and F. Kenworthy, The diary of Richard Kay, 1716-51, Manchester, Chetham Society Publications (3rd series XVI), 1968.

${ }^{3}$ Sheffield City Archives, EM 888.

4 E. Elmhirst, A peculiar inheritance, 1951, privately printed.

' Ibid. 


\section{E. M. Sigsworth and P. Swan}

the ancestral copyhold estates when his father, also called William, died in October 1746. ${ }^{6}$ The estates were considerable and, besides the income which they represented and that derived from his own immediate farming activities, William Elmhirst also received rents from tenants who mined the coal deposits which lay under his lands and which, like many in the Barnsley area, were now being increasingly exploited. While he was thus in some measure independent of his income from medical practice, this, nevertheless, was much greater than his receipts from other sources, approximately $£ 250$ per annum as compared with about $£ 50$ derived from farming and coal rentals. ${ }^{7}$ It was, by the standards of the time, a very comfortable livelihood. According to Joseph Massie's estimates for 1760, the average annual income of lawyers and innkeepers was $£ 100$ and of the wealthiest farmers $£ 150 .^{8}$ With this solid material basis, William Elmhirst was able in 1768 to extend his estates by purchasing the adjacent Ouslethwaite estate for $£ 3,000$. To be sure, the life of a country doctor, while perhaps posing few medical problems of any great rigour, could be arduous in bad weather with patients to be visited on horseback over a wide area of the surrounding countryside. William Elmhirst was killed on his rounds, being thrown from his horse at Hangmanstone Toll Bar, ${ }^{9}$ close to which he had two patients, Richard Cooper and Michael Walker. The event was recorded, not only in the Worsborough Parish Register for burials, but in the Leeds Intelligencer which attempted to provide cover for the West Riding:

On Saturday night last, as Mr. William Elmhirst, an eminent Apothecary at Ouslethwaite, near Barnsley, was returning home from a neighbour's, he, by some means fell or was thrown from his horse and kill'd on the spot. His death will be a great loss to the neighbourhood, but much more so to his disconsolate widow and children. ${ }^{10}$

The practice extended to the west and south of Barnsley and was mainly rural. Although he did have patients in Barnsley itself, they were few compared with the rest, of whom the furthest from Genn House lived approximately ten miles away as the crow flies but considerably further bearing in mind the winding roads - and a long way indeed in the mud and rain of wet weather or the cold and snow of winter. Thus, there were patients as far away as William Street of Whistone near Rotherham, George Charlesworth in Rotherham itself, and several at Grenoside, now a suburb of Sheffield. Further south than that he would doubtless encounter the activities of medical men located in Sheffield, and it is indeed surprising that he should have had patients in Rotherham where there were local practitioners in a profession in which competition had a keen cutting edge. Sheffield itself was the scene of a disgraceful episode in which two medical men came to blows, and, in consequence, to court as a result of their rivalry over the custom of a pregnant patient. ${ }^{11}$ While Trollope's

' Ibid. Also, J. Wilkinson, History of Worsborough, Barnsley and London, 1872.

I Ibid.

'P. Mathias, 'The social structure in the eighteenth century: a calculation by Joseph Massie', Econ. Hist. Rev., 1957.

' Richard Kay of Baldingstone seems frequently to have fallen off his horse. Brockbank and Kenworthy, op. cit., note 2 above.

10 Leeds Intelligencer, 20 July 1773; Worsborough registers, 19 July 1773.

"Sheffield City Archives, Tibbetts, 1096, John Hawksley and John Rutherford, assault committed in Sheffield, 1772. 
medical men did not resort to fisticuffs, their personal and professional rivalries were still intense a century after Elmhirst's death. ${ }^{12}$ Given the constraints of competition and the problems posed by horse transport and abysmal roads which the turnpikes had as yet only partly ameliorated in the area, there were clear limits to the extent of any practice. William Elmhirst's appears to have covered an area of about eleven miles by three - say approximately thirty square miles.

Who then were his patients? There is, alas, only scrappy evidence obtainable from the ledger. At one end of the social spectrum there were local landed families like the Edmonds of Worsborough Hall, ${ }^{13}$ to whom, on 4 January 1770, William Elmhirst submitted his account, carried forward from the previous ledger and covering, therefore, an unknown period of time. The entry reads:

Delivered all the above Bills to Mr. Edmonds which makes in All, when cast up together, $f 171: 11: 6$. For Inoculating Master and Miss Gowers for applications used to Little Miss Gowers Breast, Riding Charges and attendance During the time I've been Employed wd. you please fd. £171:11:6.

Similarly, there were the Phypps family, the Foulstones of Rockley Hall, Mr. Brooke of Bullah Hall, Mr. Hadfield of Old Hall, the Burkinshaws of Stanborough Hall. It may have been the case that in general the landed gentry and aristocracy procured the services of the more socially eligible physicians rather than the humbler apothecaries or surgeon-apothecaries like William Elmhirst. It may, however, have been that his own social standing as a member of an old local family conferred an advantage usually denied to members of his rank in the medical hierarchy. Perhaps also some of the entries which appear under the names of local landed families were in fact incurred for the treatment of their servants, for whom, as a general rule, apothecaries, admitted by the back door, were considered adequate, while physicians, arriving in carriages at the front portals of the house, attended members of the family. Certainly there are, in the ledger, plenty of entries relating to the treatment of servants to families whose names do not otherwise appear, like "John Moss, servant with John Robinson, Wombwell", "John Gleadle, servant with John Walker", or "Samuel Mackin, servant with John Whitworth".

At the other extreme of the social scale from the gentry and their households, William Elmhirst also acted as medical attendant to the paupers in the care of various local parishes - there are thus accounts in the ledger with the overseers of Hoyland, Dodworth, Worsborough, Silkstone, Higham, and another unspecified parish. ${ }^{14}$

Between these social extremes, the status varied of those few patients for whom relevant evidence exists. Farmers, a hand-weaver in the growing Barnsley linen industry, a wire-drawer, a painter, three tailors, a mason, and a cutter - such were the occupations which were occasionally recorded. For the great bulk of patients, however, there is nothing to indicate their rank in life other than their ability to afford

${ }^{12}$ See, for example, his novel Doctor Thorne.

${ }^{13} \mathrm{~T}$. W. Hall, Worsborough, Eckington and Sheffield, descriptive catalogue of the Edmunds Collection, Sheffield, 1924. The Edmunds family acquired the Worsborough estates in the early seventeenth century and proceeded during the next two hundred years to ally themselves "by marriage with many of the influential families in the neighbourhood." (p. 1).

${ }^{14}$ None of these accounts appears to have survived. 


\section{E. M. Sigsworth and P. Swan}

the services of a professional medical attendant. It may be, of course, that those who could not afford to pay failed to appear in the pages of the ledger and it is true that on occasion no charge was made, as for example in the account for 30 January 1769 of John Oxley of Barnsley:

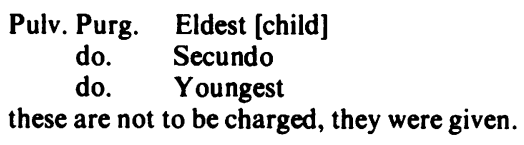

The more usual charge for this prescription of purgative powders was $1 s 4 d$ or $1 s 2 d$ per head as, for example, when three doses each were prescribed for the four children of Mr. Hall of Blackmore on 5 April 1769 - "Miss Tetty, Miss Salley, Miss Fanney and Miss Knelly".

There appears to have been a considerable element of discretion in the level of charges made, as will be seen in the cases of inoculation, but it is usually impossible to find an account cast with sufficient detail to make possible precise comparison between charges to different patients. Usually the amounts of medicine prescribed are unspecified or the account presented is the total sum for all the relevant items medicines and/or surgical treatments, travelling, and attendance.

It was not unusual, however, for payment to be made in kind. Thus, in September 1773, Richard Bellamy who owed $£ 112$ s $3 d$ for medicines was credited with 10 s $11 d$ for "a sheep for his part being the Medicines above mentioned." John Bentley of Old Barnsley, a linen-weaver, having incurred a bill for $7 s 6 d$ for the treatment of his son and borrowed $3 s$ from the surgeon, settled his bill in cloth. Francis Hill, similarly, paid his account in "coals and candles". What might otherwise have seemed a derisory payment, is explicable given William Elmhirst's agricultural activities - "Recd. load of manure in part payment from Rd. Coward, Broogreen." The Reverend Mr. Dixon offset his considerable account of $£ 279 s 6 d$ mainly for digestive medicines, with services rendered in educating William Elmhirst's three children to the value of f11 10s 10d, paying the balance in cash. To some extent, therefore, William Elmhirst received payment on a barter basis, a practice which, of course, was long continued, especially in rural areas until, indeed, the advent of a National Health Service. It would be interesting to know how far the payments in kind were negotiated as between economic equals or how far they arose from the straitened circumstances of the patient. The case of John Bentley, the Barnsley weaver, appears to foreshadow the experience of George Semple, the Shipley surgeon who complained to the 1842 House of Commons Select Committee on Truck Payments ${ }^{15}$ that his income had, in a year of depressed trade, fallen by $£ 150$, because his patients who were weavers had been compelled to pay him "in kind" which frequently meant the cloth which they had woven but were unable to sell. It was the kind of situation later dramatized by Disraeli in his novel Sybil where the "thorough Christian" doctor is faced with patients who can only pay in kind:

\footnotetext{
${ }^{15}$ Select Committee to inquire into the Operation of the Law which Prohibits the Payment of Wages in goods otherwise than in the Current Coin of the Realm, Parliamentary Papers, 1842, 10: 30.
} 


\section{William Elmhirst (1721-1773)}

"Doctor" I said, says I, "I blush to do it, but all I have got is tommy' and what shall it be, bacon or cheese?" "Cheese at tenpence a pound", says he, "which I buy for my servants at sixpence"1"

The imperfect dividing-line between cash payments and barter evident in William Elmhirst's ledger is matched by a similar haziness in the nature of the services which his skills were required to perform. Surgeon-apothecary he may have been, but he was not infrequently asked to treat animals and thereby act as a veterinary surgeon. The "drenching" of cows, horses, and dogs was the most frequent of such services:

17 September 1768. Francis Edmonds Esq.

Pro curante Abscess sub

ejus Brachio Godfrey $£ 11 s$ od

Ungt. Merc. olea pro canibus 1.0

In 1772, Mr. Cawood was charged, the item being recorded in the curious mixture of Latin and English in which the accounts are cast, for "A drench pro equam $1 s 9 d$ ".

However sharp may have been the professional lines of demarcation between physicians, surgeons, and apothecaries, the humbler levels of the medical profession apparently saw no similar status division between themselves as tending animals and human beings. As the Veterinary Record pointed out in 1846, surgeons frequently performed veterinary work prior to the establishment of the Veterinary College and claimed that "it is principally to the professors and practitioners of our elder sister Human Medicine that we are indebted for reclaiming our art from the depths of degeneration into which for centuries it had been plunged."18

The picture of actual medical practice revealed by the ledger is fairly simple. Overwhelmingly the surgeon-apothecary was called upon to prescribe medicines which he, of course, himself compounded, and of these by far the most common consisted of purgative powders. Sometimes individuals, or on occasion, as we have seen above, whole households, would be purged as William Elmhirst cantered through the Yorkshire countryside leaving a stricken clientele in his wake. Other popular remedies were anti-scorbutic medicines for the treatment of scurvy, asthmatic mixtures, digestive medicines, and various "cordials" of unspecified content. Plasters, clysters, salves, and ointments were frequently supplied, with which the more ambitious sought to cure syphilis. The usual course of treatment began with a prescription for "lotio Poxe" or Pox Lotion and proceeded with the provision of those mercurial ointments which, though fashionable at the time and for long afterwards, did little to cure the patient and much to poison him with afflictions at least as unpleasant as those from which he was suffering. Equally irrelevant, one would have thought, was the prescription of an "emplastrum" or plaster in acute cases of hernia.

In hospitals before the introduction of general anaesthesia, ${ }^{19}$ surgery was a minor part of medical practice and the range of surgery was very limited, especially where any form of incision was required - with the exception of bloodletting or, as William Elmhirst entered it in his ledger, "V.S." or "Venae sectio" - an incision in the vein. It

16 i.e., payment of wages in goods, not money.

1" B. Disraeli, Sybil or the two nations, Penguin ed.

18 Vet. Rec., 1846, 2: 20. Quoted in A. M. Carr-Saunders and P. A. Wilson, The professions, London, Clarendon Press, 1964, p. 126.

${ }^{19} \mathrm{E}$. M. Sigsworth, 'Gateways to death? Medicine, hospitals, and mortality, 1700-1850', in Peter Mathias (editor), Science and society, 1600-1900, Cambridge University Press, 1972, pp. 97-110. 


\section{E. M. Sigsworth and P. Swan}

was, and continued to be until well into the nineteenth century, a popular treatment for a wide range of complaints. For many of these it was entirely inimical, quite apart from the risk, common to all cases in which it was practised, that the wound, inflicted with an unsterile instrument, could become dangerously septic. In all, between 27 May 1769 and the ending of the ledger with William Elmhirst's death, 110 such bleedings were performed, sometimes more than once on the same patient, but only on women in two cases. ${ }^{20}$ The charge usually varied between $6 d$ and $1 s$, though on one occasion no charge was made and on another the charge was $2 s 6 d$. Sometimes the charge was recorded as including the journey, "et itinere". Otherwise, the treatments were for abscesses, strains, the occasional fracture, and unspecified wounds. William Gelder was charged 15s in April 1770 for "curing a Tumour on your kneck"; Richard Best paid $7 s 6 d$ for the "freeing" of a dislocated shoulder. James Pickworth, the innkeeper at Birchworth, had his wife's leg "resolved" for a guinea, and small boys seem to have had a talent for injuring their fingers. The catalogue of such varied and, on the whole, fairly minor treatments is short - only twenty-three cases over the fiveyear period covered by the ledger. The most serious by far seems to have been the case of Widow Mathewman's son, whose leg required twenty-one attendances. She was charged five guineas "for attendance and applications applied to the cure of your son's leg" in a bill which totalled $£ 124 s 10 d$ and which, apart from the five guineas, she refused to pay.

Only one case of major surgery is recorded - an amputation. There were no operations involving abdominal incisions, trephining of the skull, or other manifestations of the contemporary surgeon's limited repertoire. The patient in this one exception was a pauper, Thomas Gelder, of the Worsborough Workhouse. Following an unsuccessful course of treatment, his leg was amputated on 28 January 1770, the Overseers of the Poor being charged three guineas, not only for amputating but "curing" the leg and Thomas Gelder not only survived his ordeal and its risks, but was still receiving other medications some years later. There is noticeably no case recorded in which William Elmhirst attended a confinement. The only relevant entry to childbirth was an item, "To Mr. West for stating a case for Council's opinion on [Mary Allott] being pregnant. $18 s 6 d$. Postage to and from London $1 s$ [total] $19 s 6 d^{\prime \prime} .{ }^{21}$

The treatment recorded which is probably of greatest interest to the medical historian is inoculation against smallpox, especially in view of the proximity of Wharncliffe Lodge, the home of the Wortley Montague family, and its connexions with Lady Mary Wortley Montague, who in 1712 married Edward Wortley Montague. Although he did not live there, he came from the family which did so. The story of Lady Mary's pioneering activities in introducing the practice of inoculation against smallpox into Britain from Turkey, where her husband had been ambassador in Constantinople, has often been told. ${ }^{22}$ There has been considerable controversy about the extent to which the spread of this practice before the introduction of

${ }^{20}$ A clear reflection of contemporary attitudes to the undesirability of bleeding women.

21 Elmhirst journal, folio 112.

${ }_{22}$ See, for example, R. Halsband, The life of Lady Mary Wortley Montague, Oxford, Clarendon Press, 1956; and A. R. Roper (editor), Lady Mary Wortley Montague, select passages from her letters, London, 1892. 
Jenner's more successful technique of vaccination, explains a fall in the eighteenthcentury death rate of such magnitude that it alone could account for the steep rise in the British population after the $1740 \mathrm{~s}^{23} \mathrm{P}$. E. Razzell, the main proponent of this view, contends that quite apart from private practice there was, from the $1750 \mathrm{~s}$, a large increase in the numbers of people being inoculated as a result of poor-law overseers beginning to pay for the inoculation of the poor within their parishes. This practice, according to Razzell, ${ }^{21}$ became really widespread after the 1760 s, largely as the result of the activities of the Sutton family, who claimed to have inoculated 55,000 persons between 1760 and 1768, of whom only six had died. By the end of 1776, their claimed number of inoculations had risen to 300,000 and, in addition, the Suttonian practice of inoculation had been imitated not only by the rest of the medical profession, but by a wide range of amateur inoculators. ${ }^{24}$

Here we can only note that although there are large claims for the widespread nature of the activity, actual evidence for the recorded practice of inoculation has only been adduced for a limited number of places, and none has been forthcoming for Yorkshire. Abundant evidence for the practice exists, however, in the columns of the Leeds Intelligencer and Leeds Mercury. ${ }^{25}$

William Elmhirst certainly was practising inoculation, and although the record of his activities adds little to the debate, it is worth adding in an area of demographic history where there is a great deal of assertion based upon a paucity of evidence. It was not a major part of his total medical activity between 1768 and 1773 - though one might have expected it to be so in view of the chronology of the alleged rage for inoculation sweeping the country. In all he performed twenty-seven inoculations in this five-year period, plus those on the unspecified number of children belonging to Mrs. Hall of Blackmore. It is not an impressive total considering the large and wellpopulated area within which he practised. Furthermore, although he acted as medical attendant to six parishes, there is no record in his accounts with them of any mass inoculation of the poor at the behest of the overseers. To be sure, they could well have acted earlier than the extant ledger begins or after it ends, or they could have employed at any time a Suttonian inoculator other than Elmhirst. As far as his actual inoculations are concerned, the record of the ledger is as follows:

Octo 18,1768

John Hurst, Howhouses

For plaister, salves used to Child and for inoculating her, what you please. Rec. in all $\mathrm{f0} 14 s 0 d$

March 3, 1769

Wm. Parkin, Morton

March 22, 1769 pro Inoculating 3 Misses

Isaac Cusworth per Inoculating 4 Children ...

Inoculating your Children \& Applicatings thereto as you please.

\footnotetext{
${ }^{23}$ P. E. Razzell, 'Population change in eighteenth-century England: a reappraisal', Econ. Hist. Rev., 1965 , 18. See, for example, the discussion between Razzell and A. W. Downie fullowing the publication of the former's 'Edward Jenner: the history of a medical myth', Med. Hist., 1965, 9: 216-229; D. Levine, 'Some competing models of population growth during the first Industrial Revolution', J. Europ. econ. Hist., 1978, 7: 501-502.

${ }^{24}$ Razzell, 'Population change ...', op. cit., note 23 above.

${ }_{25}$ See, for example, Leeds Mercury, 18 March 1777, 10 April 1781, 26 March 1782; Leeds Intelligencer, 28 December 1773.
} 


\title{
E. M. Sigsworth and P. Swan
}

\author{
March 24, $1769 \quad$ Mr. Hall, Blackmore \\ per Inoculating 5 Children \\ January 4th, $1770 \quad$ Mr. Edmunds \\ For Inoculating Master \& Miss Jones \\ December 26th, 1770 \\ John Williams \\ For Inoculating yr. son etc. \\ Oct 27th, 1771 \\ Wm. Ellis, Hadley \\ Inoculating 6 Children \& $£ £ 33 s$ d \\ Mr. Melbourne \\ For medicine from the 17th of July 1772 to the 17th of July 1773 for your wife \\ \& self to the curing of your Disorder. For Curing Mrs. Melbourne's thigh \\ and applications thereto \& your knee. Inoculating your 10th, riding charges \\ and other ...* thereto $£ 211 s 2 d$ \\ 14th April, $1773 \quad$ Wm. Brook, Fieldhead \\ pr. Inoculating Miss $£ 1$ is $0 d$ \\ 16th June 1773 \\ Mrs. Hall, Blackmore \\ For Inoculating your Children and Attendance what you please \\ 9th August, 1773 \\ Thos. Parkinson Esq., Morronby \\ Riding Charges, Attendance and Inoculating 3 Misses what you please. \\ * illegible
}

There is about the inoculation charges a casual and indeterminate quality which transcends even the hit-or-miss methods used in determining accounts for other forms of treatment. Perhaps it was a reflection of the uncertain efficacy of the technique and the degree of consequential illness which it might cause in the patient - either from the inoculation material itself or from the risks attendant in the use of unsterilized instruments wielded by unsterile hands. "What you please", by way of recompense suggests a rather tentative approach which would not be expected were the treatment thoroughly reliable. It was not a case of benevolence to the poor, as is certain from the case of Mr. Edmunds and is suggested by the appellation "Esq." in the case of Thomas Parkinson. It is all in marked contrast to the high fees recorded as being charged by the Suttons. ${ }^{26}$ Richard charged a guinea per person if within ten miles' radius and there were not less than ten persons to be inoculated. If the number were between ten and thirty, the charge was halved, and if less than a hundred it fell to $5 s 3 d$ per capita. It was, however, his practice to charge high prices to the gentry. Richard Hoare of Boreham, Essex, paid twenty pounds in May 1769, and Mr. Dinsdale twenty-five pounds for the inoculation of his children. What is certain is that, taken altogether, William Elmhirst's practice of inoculation was unimpressive in amount either in absolute terms or as part of a thriving and widespread general medical practice, at a time when one might have expected otherwise.

There is no way of assessing what good or harm William Elmhirst wrought as he rode around the South Yorkshire countryside and, in so far as his ministrations appeared to succeed, whether this was because of, rather than in spite of them. It may seem, amidst a welter of purging and bleeding, that his activities, reflecting those of his profession at large, warrant a more pessimistic than optimistic interpretation.

${ }^{26}$ D. Van Zwanenberg, 'The Suttons and the business of inoculation', Med. Hist., 1978, 22: 71-82, p. 79. 